\title{
Shoot and root traits of summer maize hybrid varieties with higher grain yields and higher nitrogen use efficiency at low nitrogen application rates
}

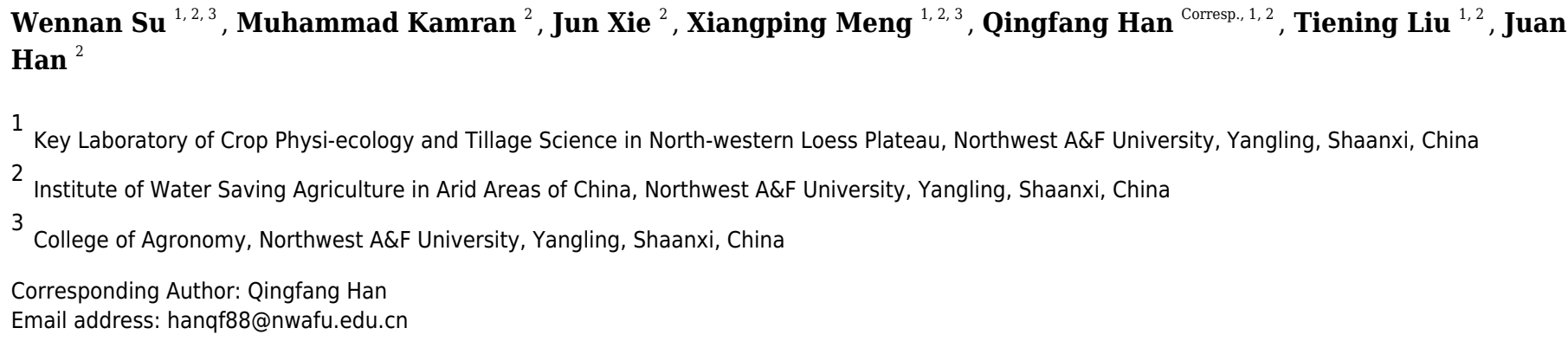

Breeding high-yielding and nitrogen-efficient maize (Zea mays L.) hybrid varieties is a strategy that could simultaneously solve the problems of resource shortages and environmental pollution. Methods. We conducted a 2-year field study using four nitrogen application rates $\left(0,150,225\right.$, and $300 \mathrm{~kg} \mathrm{~N} \mathrm{hm}^{-2}$ ) and two maize hybrid varieties (ZD958 and QS101) to understand the plant traits related to high grain yields and high nitrogen use efficiency (NUE).We found that ZD958 had a higher grain yield and nitrogen accumulation in the shoots at harvest as well as a higher NUE at lower nitrogen application rates $\left(0\right.$ and $150 \mathrm{~kg} \mathrm{hm}^{-2}$ ) than QS101. The grain yields and NUE were almost identical for the two hybrid varieties at nitrogen application rates of 225 and $300 \mathrm{~kg} \mathrm{~N} \mathrm{hm}^{-2}$. Compared with QS101, ZD958 had higher above-ground and below-ground biomass amounts, a deeper root distribution, longer root length, root active absorption area, greater grain filling rate, and higher photosynthetic NUE than QS101 at lower nitrogen application rates. Our results showed that ZD958 can keep maintain a higher grain yield at lower nitrogen rates in a similar manner to $\mathrm{N}$-efficient maize hybrid varieties. The selection of hybrids such as ZD958 with a deeper root distribution and higher photosynthetic NUE can increase the grain yield and NUE under low nitrogen conditions. 
2 Shoot and root traits of summer maize hybrid varieties

3 with higher grain yields and higher nitrogen use

4 efficiency at low nitrogen application rates

5

6

7

Wennan $\mathrm{Su}^{1,2,3}$, Kamran Muhammad ${ }^{2}$, Jun Xie², Xiangping Meng ${ }^{1,2,3}$, Qingfang Han ${ }^{1,2}$, Tiening Liu ${ }^{1,2}$, Juan Han ${ }^{2}$

${ }^{1}$ Key Laboratory of Crop Physi-ecology and Tillage Science in North-western Loess Plateau, Northwest A\&F University, Yangling, Shaanxi, China

${ }^{2}$ Institute of Water Saving Agriculture in Arid Areas of China, Northwest A\&F University, Yangling, Shaanxi, China

${ }^{3}$ College of Agronomy, Northwest A\&F University, Yangling, Shaanxi, China

Corresponding Author:

Qingfang Han ${ }^{1,2}$

Yangling, Shaanxi, China

Email address: hanqf88@nwafu.edu.cn

\section{Abstract}

Breeding high-yielding and nitrogen-efficient maize (Zea mays L.) hybrid varieties is a strategy that could simultaneously solve the problems of resource shortages and environmental pollution. Methods. We conducted a 2-year field study using four nitrogen application rates $(0,150,225$, and $300 \mathrm{~kg} \mathrm{~N} \mathrm{hm}^{-2}$ ) and two maize hybrid varieties (ZD958 and QS101) to understand the plant traits related to high grain yields and high nitrogen use efficiency (NUE).We found that ZD958 had a higher grain yield and nitrogen accumulation in the shoots at harvest as well as a higher NUE at lower nitrogen application rates $\left(0\right.$ and $\left.150 \mathrm{~kg} \mathrm{hm}^{-2}\right)$ than QS101. The grain yields and NUE were almost identical for the two hybrid varieties at nitrogen application rates of 225 and $300 \mathrm{~kg} \mathrm{~N} \mathrm{hm}^{-2}$. Compared with QS101, ZD958 had higher above-ground and below-ground biomass amounts, a deeper root distribution, longer root length, root active absorption area, greater grain filling rate, and higher photosynthetic NUE than QS101 at lower nitrogen application rates. Our results showed that ZD958 can keep maintain a higher grain yield at lower nitrogen rates in a similar manner to $\mathrm{N}$-efficient maize hybrid varieties. The selection of hybrids such as ZD958 with a deeper root distribution and higher photosynthetic NUE can increase the grain yield and NUE under low nitrogen conditions.

\section{Introduction}

Tester and Langridge (2010) predicted that the global demand for food will increase by $70 \%$ by 2050 , and thus there is an urgent need to address the problem of resource shortages in order to meet future human needs (Good, 2004). Nitrogen fertilizer is the largest input resource for 
agricultural production and it greatly improves crop yields (Guo et al., 2010). At present, the nitrogen fertilizer application rate far exceeds the appropriate range in China (Fang et al., 2010). The high nitrogen fertilizer application rate and low nitrogen use efficiency (NUE) have caused groundwater and air pollution in many regions of China (Cui et al., 2010; Zhang et al., 2016). Therefore, environmental and resource constraints mean that further increases in agricultural production should be achieved by increasing the NUE rather than higher nitrogen inputs (Hawkesford, 2014).

In 2005, China accounted for $38 \%$ of the global nitrogen consumptions but it only has $9 \%$ of the world's arable land (FAO, 2011). Nitrogen fertilization-induced increases in grain yields have been decreasing each year in China. Thus, the agricultural NUE decreased from $25 \mathrm{~kg} \mathrm{~kg}^{-1}$ during 1958-1962 to $8 \mathrm{~kg} \mathrm{~kg}^{-1}$ during 1997-2003, which was significantly below than the lower limit of the internationally recognized agricultural NUE range $\left(10-30 \mathrm{~kg} \mathrm{~kg}^{-1}\right)$ (Dobermann, 2005). The NUE can be improved by adjusting the fertilization method employed, period, or types (Abbasi et al., 2013; Zhao et al., 2013). Ciampitti and Vyn $(2012,2013)$ concluded that modern varieties obtain relatively higher NUE levels than old varieties. However, the modern breeding process is usually conducted on fertile soil or soil with high nitrogen fertilizer inputs, and breeders have mainly focused on nitrogen absorption by plants and grain yields (Berlin \& Gallais, 2000), whereas they have neglected the performance of hybrid varieties under low nitrogen conditions.

The selection of N-efficient hybrid varieties (hybrids with higher grain yield under low $\mathrm{N}$ condition (Wu et al., 2011)) plays a significant role in improving the NUE. Differences in nitrogen uptake and utilization vary significantly among genotypes (Kant et al., 2011; Bingham et al., 2012), which are reflected in the responses of different varieties to nitrogen application, as well as in the distribution and utilization of nitrogen in crops (Gallais \& Coque, 2005). However, there is still no general conclusion regarding the characteristics of high grain yield and high NUE plants under low nitrogen conditions.

Roots play a supporting and fixing role in the soil, but they are also important organs that allow plants to capture water and nutrients from the soil (Lynch, 2013; White et al., 2013). Previous studies of roots have investigated the possibility of further improving crop productivity and the NUE. The growth and distribution of roots are determined by genetic characteristics, and they are also influenced by environmental factors. The morphology of roots is closely related to the acquisition of soil resources and the development of plant shoots (Mi et al., 2010; Lynch, 2013; Li et al., 2017). The effects of various factors mean that roots respond to nitrogen in significantly different manners in field trials compared with culture experiments (Wang et al., 2003; Tian et al., 2005). The effects of nitrogen application on the roots are inconsistent under field conditions, where some studies suggest that nitrogen application can promote root growth, whereas others indicate that it can inhibit the growth of the root system (Chen et al., 2015; Feng et al., 2016). There are reports showing that several plant shoot traits could also be associated with grain yield and NUE in selecting for improving grain yield under low nitrogen conditions (Banziger \& Lafitte, 1997; Haegele et al., 2013; Chen et al., 2016; Talabi et al., 2017), such as 
79 leaf longevity (stay-green), anthesis-silking interval, leaf chlorophyll concentration, grain $\mathrm{N}$

80 accumulation and also number of kernels per ear. Banziger et al. (2006) and Morosini et al.

81 (2017) suggested that the development of low-N tolerant and N-efficient genotypes can result in

82 significant breeding progress. However, there have been few systematic studies of the shoots and 83 roots on the NUE in maize under field conditions.

84 In this study, we determined the characteristics of the shoots and roots in maize with high 85 yield and high NUE under lower nitrogen application rates. These results obtained in this study 86 provide insights into the mechanisms responsible for high grain yields and high NUE in maize, 87 thereby providing a theoretical basis to allow breeders to improve the NUE without reducing the 88 potential grain yield.

\section{Materials and Methods}

90

91

92

93

94

95

96

97

98

99

100

101

102

103

104

105

106

107

108

109

110

111

112

113

114

115

116

117

\section{Field experiments}

Field experiments were conducted at the Agricultural Experimental Station of Northwest Agricultural and Forestry University $\left(34^{\circ} 21^{\prime} \mathrm{N}, 108^{\circ} 10^{\circ} \mathrm{E}, 454.8 \mathrm{~m}\right.$ altitude), Shaanxi province, northwest China during the maize growing season (June to October) of 2014 and 2015. The soil at the experimental site was loam soil with the following chemical properties in the top $60 \mathrm{~cm}$ soil layer at the start of the experiment: organic matter content, $14.3 \mathrm{~g} \mathrm{~kg}^{-1}$; total $\mathrm{N}, 1.09 \mathrm{~g} \mathrm{~kg}^{-1}$; Olsen-P, $9.4 \mathrm{mg} \mathrm{kg}^{-1}$; and $\mathrm{NH}_{4} \mathrm{OAc}-\mathrm{K}, 127 \mathrm{mg} \mathrm{kg}^{-1}$.

The experimental design was a randomized block with three replications. Each plot comprised one row with a length of $8 \mathrm{~m}$ and a row spacing of $60 \mathrm{~cm}$, and the plants were spaced $25 \mathrm{~cm}$ apart. Two high-yielding maize varieties currently used for local production were selected as the typical contemporary maize hybrids: Zhengdan958 (ZD958: N-efficient hybrid) and

Qiangsheng101 (QS101: N-inefficient hybrid). And the two maize hybrids have the same growth period. Plots were planted manually with two seeds per hill on June 17, 2014, and June 15, 2015. They were thinned to obtain the desired plant population ( $67500 \mathrm{pl}$. ha) at V3. The date of harvest was October 14, 2014 and October 15, 2015. Fertilizer N was sourced from urea (46\% $\mathrm{N})$, evenly split in the fractions of $1 / 2$ at pre-sowing and side-banded deep $(5 \mathrm{~cm})$ into the soil on the sowing rows of $1 / 2$ at twelve-leaf stage. In addition, $150 \mathrm{~kg}$ phosphorus $\left(\mathrm{P}_{2} \mathrm{O}_{5}\right) \mathrm{hm}^{-2}$ as calcium superphosphate $\left(\mathrm{P}_{2} \mathrm{O}_{5} 16 \%\right)$ and $150 \mathrm{~kg}$ potassium $\left(\mathrm{K}_{2} \mathrm{O}\right) \mathrm{hm}^{-2}$ as potassium sulfate $\left(\mathrm{K}_{2} \mathrm{O} 45 \%\right)$ were applied at pre-sowing. Irrigation was applied when the remaining $50 \%$ of urea (N $46 \%$ ) was applied. Plots were kept free of weeds, insects, and diseases according to standard practices. Weather data were obtained from a local weather station approximately $100 \mathrm{~m}$ from the experimental field. The daily mean precipitation and temperature data during the two growing seasons are presented in Figure 1. During the two growing seasons, the effective accumulated temperatures were $1617^{\circ} \mathrm{C}$ and $1565^{\circ} \mathrm{C}$ in 2014 and 2015 , respectively, and the total precipitation levels were $217 \mathrm{~mm}$ and $299 \mathrm{~mm}$.

Sampling and measurements Net photosynthetic rate (Pn) and photosynthetic nitrogen use efficiency (PNUE) 
118 At anthesis from 10:00 to 12:00, three representative plants were selected from each plot and the

119 Pn values of the ear leaves were measured with a portable infrared gas exchange-based

120 photosynthesis analyzer system LI-6400 (LI-COR, Lincoln, NE, USA) while avoiding the midrib

121 (prevent leaf chamber leakage), which was coupled with a standard red/blue LED broadleaf

122 cuvette (6400-02B, LI-COR), under a consistent controlled light intensity of $1300 \mathrm{mmol} \mathrm{m}^{-2} \mathrm{~s}^{-1}$.

123 After obtaining the photosynthesis measurements, the leaves were harvested to determine the

124 leaf area. The veins were then removed and the remaining parts were mixed and heated at $105^{\circ} \mathrm{C}$

125 for $30 \mathrm{~min}$, before drying to constant weight at $70^{\circ} \mathrm{C}$. After determining the dry weight, the

126 sample was ground into powder and the nitrogen concentration was obtained using the Kjeldahl

127 method. Based on the leaf dry weight, leaf area, and nitrogen concentration, we calculated the

128 leaf specific nitrogen $\left(\mathrm{SLN}\left(\mathrm{g} \mathrm{N} \mathrm{m}^{-2}\right)=\right.$ leaf nitrogen content $(\mathrm{g}) / \mathrm{leaf}$ area $\left.\left(\mathrm{m}^{2}\right)\right)$ and PNUE

$129\left(\left(\mu \mathrm{mol} \mathrm{CO} 2 \cdot \mathrm{g}^{-1} \mathrm{~N} \mathrm{~s}^{-1}\right)=\right.$ Pn of ear leaves $\left.\left(\mu \mathrm{mol} \mathrm{m}^{-2} \mathrm{~s}^{-1}\right) / \mathrm{SLN}\left(\mathrm{g} \mathrm{N} \mathrm{m}^{-2}\right)\right)$ (Sinclair and Horie,

130 1989).

131 Root length, dry weight and active absorption area

132 At anthesis, three representative and adjacent maize plants were selected in each plot the shoots

133 were collected and the root system was excavated to a depth of $60 \mathrm{~cm}$, where it was divided into

134 three layers at every $20 \mathrm{~cm}$ using the soil profile method. In order to minimize any sampling and

135 measurement errors, each root system was excavated from an area of $0.15 \mathrm{~m}^{2}$ (length $=0.6 \mathrm{~m}$,

136 width $=0.25 \mathrm{~m}$ ). The excavated roots were washed and enclosed in a plastic bag, before

137 scanning using a root scanner (with WinRHIZO scanning software). Then the dry weight was

138 determined after drying in an oven. Each scanned root image was processed using a root analysis

139 program (Regent Instruments Inc. WinRHIZO Pro 2007d) to obtain the root length in each layer

140 (Chen et al., 2015). The shoots were heated at $105^{\circ} \mathrm{C}$ for $30 \mathrm{~min}$ and then dried to constant

141 weight at $70^{\circ} \mathrm{C}$ before weighing. Root active absorption area were determined by methylene blue

142 dyeing method (Zhang et al., 1994).

143 Grain filling characteristics

144 During 2014 and 2015, beginning 4 days after anthesis, three tagged ears were sampled per 145 plot every 4 days until the grain reached physiological maturity. The grain in each row was 146 selected and stripped, before counting the total number of kernels removed from each ear. The 147 kernels were dried until constant weight in an oven at $75^{\circ} \mathrm{C}$ and then weighed with a balance.

148 Shoot biomass and grain yield

149 At maturity (when black layer formation was complete in all plants), the grain yield was 150 determined using plants from four undisturbed rows, where the plants on each side of the plot 151 were discarded to avoid border effects, and grain yield was expressed at $14 \%$ moisture.. Twenty 152 plants in each plot were used to determine the kernel number and 100-grain dry weight. The dry 153 weights of shoots from each plant were determined by oven-drying to constant weight at $75^{\circ} \mathrm{C}$. 154 The plant nitrogen concentration was determined with the micro-Kjeldahl method (as described 155 by Nelson and Sommers (1973)), distillation, and titration to calculate the shoot $\mathrm{N}$ uptake.The 156 NUE was calculated according to the methods described by Xue et al. (2013) as well as the 157 following. 
158 Agronomic efficiency of nitrogen fertilizer $\left(\mathrm{AEN}, \mathrm{kg} \mathrm{kg}^{-1}\right)=$ (grain yield with nitrogen

159 application - grain yield without nitrogen application) /amount of nitrogen applied

160 Nitrogen partial factor productivity (PFPN, $\mathrm{kg} \mathrm{kg}^{-1}$ ) $=$ grain yield /amount of nitrogen applied

161 Nitrogen utilization efficiency (NUtE, $\mathrm{kg} \mathrm{kg}^{-1}$ ) = grain yield /nitrogen uptake by shoots at

162 maturity

\section{Statistical analysis}

164 The effects of treatments (hybrid variety and nitrogen application rate) and their interactions

165 were compared with analysis of variance (ANOVAs) for related traits performed in 2014 and

1662015 using SPSS 18.0 software (SPSS Inc., Chicago, IL).. Multiple comparisons were performed

167 using Duncan's multiple range test and differences were considered statistically significant at $P$ $168<0.05$.

169 We analyzed the kernel dry weight dynamics using the logistic equation (Gu et al., 2001) in 170 Eq. (1):

$171 \mathrm{~W}=\frac{A}{\left(1+B e^{-C t}\right)^{\frac{1}{0}}}$,

172 Where $\mathrm{W}$ is the measured kernel dry weight $(\mathrm{mg}), \mathrm{t}$ is the number of days after anthesis, $\mathrm{A}$ is 173 the final kernel weight, $\mathrm{B}$ is the initial value parameter, and $\mathrm{C}$ is the growth rate parameter. We 174 calculated the following grain filling characteristic parameters (Wang et al., 2014).

175 Days required to reach the maximum grain filling rate (Tmax, d) (2)

176

$$
\operatorname{Tmax}=\frac{\ln B}{C}
$$

177

178

Grain weight at the maximum grain filling rate (Wmax, $\mathrm{mg}$ ) (3)

179

180

$$
\text { Wmax }=\frac{\mathrm{A}}{2}
$$

Maximum grain-filling rate (Gmax, $\mathrm{mg} \mathrm{grain}^{-1}$ day $\left.^{-1}\right)(4)$

$$
\text { Gmax }=C \times W \max -\frac{C \times W \max ^{2}}{A}
$$

Final grain filling time (time taken for the grain weight to reach $99 \%$ (T0.99, days)) (5)

$$
\mathrm{T} 0.99=\frac{\ln B+4.59512}{C}
$$

$$
\mathrm{W} 1=\frac{A}{\left(1+B e^{-C T 0.99}\right)^{\frac{1}{D}}}
$$

Average grain filling rate $\left(\right.$ Gave, $\mathrm{mg} \mathrm{grain}^{-1}$ day $\left.^{-1}\right)(7)$

$$
\text { Gave }=\frac{\mathrm{W} 1}{\mathrm{~T} 0.99}
$$

187 The curves of the kernel dry weight dynamics were performed using SPSS 18.0 (SPSS Inc., 188 Chicago, IL).

189 Results

190 Variance analysis 
191 Table 1 shows the grain yield, yield components, shoot nitrogen uptake, and NUE in both years. 192 The hybrid varieties, nitrogen application rate, and their interactions had significant effects $(P<$ 193 0.05) on the different variables (except for the kernel number). Measurements of other indicators 194 with similar results are not presented.

\section{Grain yield and nitrogen use efficiency (NUE)}

196 As shown in Table 2, at lower nitrogen application rates (N0 and N150), the grain yields were 197 significantly higher for ZD958 than QS101 at the same $\mathrm{N}$ rate $(P<0.05)$ There were no 198 significant differences $(P \geq 0.05)$ in the grain yields from both hybrid varieties under normal nitrogen application rates and higher application rates (N225 and N300) in both years. The grain

200

201

202

203

204

205

206

207

208

209

210

211

212

213

214

215

216

217

218

219

220

221

222

223

224

225

226

227

228

229

230

yield was higher at lower nitrogen rates with ZD958, which was mainly attributed to higher 100grain weight rather than the number of kernels compared with QS101 (Table 2).

Similar to the grain yield, the shoot nitrogen uptake, NUtE, and PFPN were significantly higher for ZD958 than QS101 at lower nitrogen application rates. These indicators did not differ significantly between the two hybrid varieties at N225 and N300 (Table 3). The AEN values were similar for the two hybrids under N150. ZD958 had lower AEN values than QS101 under the N225 and N300 treatments, mainly because QS101 had a much lower grain yield than that ZD958 with nil nitrogen application. Thus, at low nitrogen rates, ZD958 with high grain yield and NUE defined as an N-efficient maize hybrid, whereas QS101 with low grain yield and NUE was defined as an N-inefficient maize hybrid. This confirms the choice of both hybrids.

\section{Shoots and roots}

Figure 2 shows the shoot and root biomasses and root/shoot ratios at anthesis. At lower nitrogen application rates, the shoot and root biomasses were significantly higher with ZD958 than QS101. These parameters did not differ significantly between the two hybrid varieties at N225 and N300 in both years.

At maturity, the shoot biomass was significantly greater with ZD958 than QS101 under the N0 and N150 treatments. Under N225 and N300, the shoot biomass did not differ significantly between the two hybrid varieties. At the same nitrogen rate, there was no significant difference in the root/shoot ratio between the two varieties. The root/shoot ratio increased initially and then decreased as the nitrogen application rate increased for the same hybrid variety.

Figure 3-5 show the root dry weights, root lengths and root active absorption area for the two hybrid varieties under different nitrogen application rates in both years. Under the N0 and N150 treatments, the root dry weight and root length in the $0-60 \mathrm{~cm}$ soil depth were significantly higher for ZD958 than QS101. The root dry weight and root length in the $0-60 \mathrm{~cm}$ soil depth did not differ significantly between the two hybrid varieties under the N225 and N300 treatments, and they also did not differ significantly in the same hybrid between the N225 and N300 treatments. Moreover, the differences in the root dry weight and root length in the $0-20 \mathrm{~cm}$ soil depth were not significant between the two hybrid varieties under all of the nitrogen rates, whereas they differed significantly in the $20-60 \mathrm{~cm}$ soil depth. Thus, the differences between the two hybrid varieties under the $\mathrm{N} 0$ and $\mathrm{N} 150$ treatments were related to differences in the deeper roots. The root dry weight and root length increased as the nitrogen application rate increased, 
231

232

233

234

235

236

237

238

239

240

241

242

243

244

245

246

247

248

249

250

251

252

253

254

255

256

257

258

259

260

261

262

263

264

265

266

267

268

269

270

and then decreased. Compared with the N225 treatment, the root dry weight and root length in the $0-60 \mathrm{~cm}$ soil depth were significantly different in the N300 treatment because the root dry weight in the 20-60 cm soil depth was significantly lower compared with that in the N225 treatment for both hybrid varieties (Fig. 3 and 4). Similar to root dry weight and root length, root active absorption area of QS101 in the $20-40 \mathrm{~cm}$ and $40-60 \mathrm{~cm}$ soil layers decreased were significantly lower than those of ZD958 under N0 and N150 treatments (Fig.3-5).

\section{Leaf specific nitrogen (SLN), net photosynthetic rate (Pn), and photosynthetic nitrogen use efficiency (PNUE)}

The SLN, Pn, and PNUE results are shown in Figure 5. Under the N0 and N150 treatments, SLN was significantly higher for ZD958 than QS101, but there were no significant difference between the two hybrid varieties under N225 and N300. Similar to SLN, the Pn and PNUE values were significantly higher for ZD958 than QS101 under the N0 and N150 treatments. The differences between the two hybrid varieties were not significant for Pn and PNUE in N225 and N300. SLN and Pn tended to increase with the nitrogen application rate, whereas PNUE exhibited a decreasing trend (Fig. 6).

\section{Grain filling characteristics}

Table 4 shows the grain filling parameters for the two hybrid varieties under different nitrogen application rates. Under N0 and N150 treatments, ZD958 exhibited a higher maximum grain filling rate (Gmax, mg grain ${ }^{-1} \mathrm{~d}^{-1}$ ), average grain-filling rate (Gave, $\mathrm{mg}$ grain ${ }^{-1} \mathrm{~d}^{-1}$ ), and kernel weight at the maximum grain filling rate (Wmax, $\mathrm{mg}$ ) than QS101. QS101 required more days to reach the maximum grain filling rate (Tmax, d) than ZD958.

\section{Discussion}

Many studies have shown that the application of nitrogen fertilizer can improve the photosynthetic capacity, nitrogen content, total biomass, and grain yield but decrease the NUE (Peng et al., 2016; Hammad et al., 2017). Similar to previous studies, our results showed that the application of N300 increased the grain yield by $2-15 \%$ compared with N150. The PFPN value under the N300 treatment was decreased by $42-49 \%$ compared with the N150 treatment in both hybrid varieties (average of two years). Previous studies have rarely reported details of the plant traits related to high grain yields and high NUE levels in maize hybrid varieties under low nitrogen application rates.

It is well known that the NUE can be simply defined as the increase in the amount of nitrogen that plants obtain from soil, or it can be defined as the more efficient use of absorbed nitrogen (Garnett et al., 2009). Breeding hybrid varieties with both traits (especially under nitrogendeficient conditions) will be beneficial for agricultural sustainability (Garnett et al., 2009; Kant et al., 2011). In this study, ZD958 obtained a higher yield than QS101 at low nitrogen rates (N0 and N150) and it absorbed more nitrogen from the soil while maintaining a higher NUE. These results indicate the possibility of developing maize hybrid varieties with both higher nitrogen uptake efficiencies and higher NUE levels. The grain yield increases of hybrid varieties with high-yielding and high NUE range from $8 \%$ to $10 \%$, and they can reduce the application of nitrogen fertilizer by $16 \%$, thereby demonstrating that it is feasible to cultivate new high yield 
271 and high NUE maize varieties (Chen et al., 2013). Adu et al. (2018) also suggested maize grain 272 yield could increase under low-N supply at the same time maintaining the grain yield potential 273 under high-N conditions is achievable when NUE genotypes are adopted.

274 Most previous studies of the NUE in maize were conducted in potting conditions and few 275 studies investigated the shoot and root systems in hybrid varieties under field conditions. The 276 growth of plant shoots is closely associated with the size of the root system. Larger roots are 277

278

279

280

281

282

283

284

285

286

287

288

289

290

291

292

293

294

295

296

297

298

299

300

301

302

303

304

305

306

307

308

309 often beneficial for absorbing nutrients, thereby leading to a higher shoot biomass. The size and morphology of the roots affect the absorption of nutrients, and the root length is an important indicator of the effectiveness of root interception to acquire nitrogen. Thus, genotypes that exhibit greater nitrogen uptake have a large root system, especially longer roots (Li et al., 2017; Duan, 2019). In this study, under the low nitrogen conditions, we observed that the N-efficient maize hybrid ZD958 had longer roots, higher root dry weights and root active absorption area than the N-inefficient maize hybrid QS101 at lower N rates, which was mainly attributable to the longer roots and higher root dry weight in the $20-60 \mathrm{~cm}$ soil depth. These findings suggest that the N-efficient maize hybrid had a greater capacity for growing longer roots, which was reflected by the aboveground performance in terms of its greater shoot biomass and grain filling rate compared with QS101. A variety with a greater capacity for growing longer roots can maximize the capture of nitrogen from the soil (Garnett et al., 2009; Mi et al., 2010), and we found that the nitrogen content and shoot biomass of ZD958 was significantly higher than that of QS101. Studies also have shown that the deep root environment of the soil was relatively stable, which helps to enhance the buffering capacity to the adverse soil environment (Wasson et al., 2012), improve the stress resistance, delay root senescence, and maintain root nutrient and water supply to the shoot, obtain high grain yield (Saengwilai et al., 2014).Therefore, we conclude that under low nitrogen conditions, larger shoot and root biomasses as well as higher grain filling rates will contribute to better grain yields, and thus higher NUE levels for N-efficient maize hybrids.

The supply of nitrogen affects the growth of roots. Numerous studies have investigated the effects of the nitrogen supply on the growth of maize roots under field conditions (Tian et al., 2006; Wu et al., 2011; Liu et al., 2017). Nitrogen application has a positive effect on root growth (Liu et al., 2009; York et al., 2015) but also adverse effects when provided in excess (Tian et al., 2008; Chen et al., 2015). Root growth has a parabolic linear relationship with the nitrogen application rate and excessive nitrogen application limits the growth of the root system (Feng et al., 2016). Our results are similar to those obtained in previous studies. The length and dry weight of the maize roots increased with the nitrogen application rate, but the length of the roots decreased in the N300 treatment (Fig. 3 and 4), where this difference occurred mainly in the 20$60 \mathrm{~cm}$ soil depth. The root system was obviously shallower in the N300 treatment than the N225 treatment and it was mostly distributed in the upper part of the soil. The root length and root dry weight were also small, especially the root length in the N300 treatment. The same trend was observed for both genotypes. This could explain why the maize grain yield did not increase under higher nitrogen conditions. 
Previous studies showed that N-efficient maize varieties obtained higher PNUE values (Echarte et al., 2008; Chen et al., 2014). Similar to previous studies, we determined differences in SLN and Pn between the two hybrid varieties. PNUE can be expressed as the ratio of Pn relative to SLN. At the low nitrogen rate, ZD958 had higher SLN and Pn as well as PNUE values, which indicated that the higher PNUE was attributed to a higher Pn value. A higher PNUE can increase the grain filling rate and plant biomass, but also the NUE. The physiological mechanism responsible for the higher PNUE in N-efficient maize hybrids under low nitrogen conditions is not clear. However, it is possible that hybrid varieties with higher PNUE values can allocate less nitrogen to their non-photosynthetic components than hybrids with lower PNUE values (Hikosaka, 2004; Mu et al., 2016). In this study, we only investigated two varieties that differed significantly in terms of their performance under low nitrogen conditions. The selection of varieties was limited and thus it would be useful to select more varieties for further assessments.

\section{Conclusions}

In this study, low nitrogen application rates substantially reduced shoot and root growth, nitrogen uptake, and the grain yield in maize. The N-efficient maize hybrid variety obtained a higher grain yield, greater shoot nitrogen uptake to the shoots from the soil, and a higher NUE at low nitrogen application rates. Higher root and shoot biomasses, a deeper root distribution, longer root length, root active absorption area, and a higher leaf PNUE are beneficial for the grain yield and NUE. Thus, it is possible to obtain a high grain yield and NUE in maize under low nitrogen conditions. The plant traits comprising a higher PNUE and deeper root distribution can be used as selection criteria in breeding programs to select $\mathrm{N}$-efficient hybrid varieties for growth in low nitrogen conditions.

\section{Acknowledgements}

We would like to thank the reviewers for helping us to improve our original manuscript, and also grateful to Ding Ruixia, Nie Junfeng, and Yang Baoping for field work assistance during experimental period.

\section{References}

Abbasi MK, Tahir MM, Rahim N. 2013. Effect of nitrogen fertilizer source and timing on yield and $\mathrm{N}$ use efficiency of rained maize (Zea mays L.) in Kashmir- Pakistan. Geoderma 195196:87-93 DOI 10.1016/j.geoderma.2012.11.013.

Adu GB, Alidu H, Amegbor IK, Abdulai MS, Nutsugah SK, Obeng-Antwi K, Kanton RAL, Buah SS, Kombiok MJ, Abudulai M, Etwire PM. 2018. Performance of maize populations under different nitrogen rates in northern Ghana. Annals of Agricultural Sciences 63(2):145-152 DOI 10.1016/j.aoas.2018.10.001. 
347

348

349

350

351

352

353

354

355

356

357

358

359

360

361

362

363

364

365

366

367

368

369

370

371

372

373

374

375

376

377

378

379

380

381

382

383

384

385

386

Banziger M, Lafitte HR. 1997. Efficiency of secondary traits for improving maize for lownitrogen target environments. Crop Science 37(4):1110-1117 DOI 10.2135/cropsci1997.0011183X003700040013x.

Banziger M, Setimela PS, Hodson D, Vivek B. 2006. Breeding for improved abiotic stress tolerance in maize adapted to southern Africa. Agricultural Water Management 80: 212-224 DOI 10.1016/j.agwat.2005.07.014.

Bingham IJ, Karley AJ, White PJ, Thomas WTB, Russell JR. 2012. Analysis of improvements in nitrogen use efficiency associated with 75 years of spring barley breeding. European Journal of Agronomy 42:49-58 DOI 10.1016/j.eja.2011.10.003.

Chen FJ, Fang ZG, Gao Q, Ye YL, Jia LL, Yuan LX, Mi GH, Zhang FS. 2013. Evaluation of the yield and nitrogen use efficiency of the dominant maize hybrids grown in North and Northeast China. Science China-Life Science 56(6): 552-560 DOI 10.1007/s11427-0134462-8.

Chen K, Camberato JJ, Tuinstra MR, Kumudini SV, Tollenaar M, Vyn TJ. 2016. Genetic improvement in density and nitrogen stress tolerance traits over 38 years of commercial maize hybrid release. Field Crops Research 196:438-451 DOI 10.1016/j.fcr.2016.07.025.

Chen YL, Xiao CX, Chen XC, Li Q, Zhang J, Chen FJ, Yuan LX, Mi GH. 2014. Characterization of the plant traits contributed to high grain yield and high grain nitrogen concentration in maize. Field Crops Research 159:1-9 DOI 10.1016/j.fcr.2014.01.002.

Chen YL, Zhang J, Li Q, He XL, Su XP, Chen FJ, Yuan LX, Mi GH. 2015. Effects of nitrogen application on post-silking root senescence and yield of maize. Agronomy Journal 107(3): 835-842 DOI 10.2134/agronj14.0509.

Ciampitti LA, Vyn TJ. 2012. Physiological perspectives of changes over time in maize yield dependency on nitrogen uptake and associated nitrogen efficiency: a review. Field Crops Research 133:48-67 DOI 10.1016/j.fcr.2012.03.008.

Ciampitti LA, Vyn TJ. 2013. Grain nitrogen source changes over Time in maize: A review. Crop Science 53(2): 366-377 DOI 10.2135/cropsci2012.07.0439.

Cui ZL, Zhang FS, Chen XP, Dou ZX, Li JL. 2010. In-season nitrogen management strategy for winter wheat: Maximizing yields, minimizing environmental impact in an over-fertilization context. Field Crops Research 116:140-146 DOI 10.1016/j.fcr.2009.12.004.

Dobermann A. 2005. Nitrogen use efficiency-state of the art. Paper of the IFA international workshop on enhanced-efficiency fertilizers. Frankfurt, Germans.Duan PF. 2019. Response of maize genotypes with different nitrogen use efficiency to low nitrogen stresses. Acta Ecologica Sinica 39(1):77-80 DOI 10.1016/j.chnaes.2018.05.005.

Echarte L, Rothstein S, Tollenaar M. 2008. The response of leaf photosynthesis and biomass accumulation to nitrogen supply in an older and a newer maize hybrid. Crop Science 48: 656-665 DOI 10.2135/cropsci2007.06.0366.

Fang QX, Ma L, Green TR, Yu Q, Wang TD, Ahuja LR. 2010. Water resources and water use efficiency in the North China Plain: Current status and agronomic management options. Agricultural Water Management 97(8): 1102-1116 DOI 10.1016/j.agwat.2010.01.008. 
387 388 389 390 391 392 393 394 395 396 397 398 399 400 401 402 403 404 405 406 407 408 409 410 411 412 413 414 415 416 417 418 419 420 421 422 423 424 425 426

FAOSTAT, 2011. Production Statistics. Food and Agriculture Organization of the United Nations, http://faostat.fao.org/site/567/default.aspx\#ancor.

Feng GZ, Zhang YJ, Chen YL, Li Q, Chen FJ, Gao Q, Mi GH. 2016. Effects of nitrogen application on root length and grain yield of rain-fed maize under different soil types. Agronomy Journal 108(4): 1656-1665 DOI 10.2134/agronj2015.0367.

Gallais A, Coque M. 2005. Genetic variation and selection for nitrogen use efficiency in maize: a synthesis. Maydica 50(3):531-547 DOI 10.1007/3-7643-7380-6_17.

Garnett T, Conn V, Kaiser BN. 2009. Root based approaches to improving nitrogen use efficiency in plants. Plant Cell Environment 32(9): 1272-1283 DOI 10.1111/j.13653040.2009.02011.x.

Good AG, Shrawat AK, Muench DG. 2004. Can less yield more? Is reducing nutrient input into the environment compatible with maintaining crop production? Trends Plant Science 9(12):597-605 DOI 10.1016/j.tplants.2004.10.008.

Gu SL, Zhu QS, Yang JC, Peng SB. 2001. Analysis on grain filling characteristics for different rice types. Acta Agronomica Sinica, 27(1): 7-14 (in Chinese with English abstract).

Guo JH, Liu XJ, Zhang Y, Shen JL, Han WX, Zhang WF, Christie P, Goulding KWT, Vitousek PM, Zhang FS. 2010. Significant acidification in major Chinese croplands. Science 327(5968):1008-1010 DOI 10.1126/science.1182570.

Haegele JW, Cook KA, Nichols DM, Below FE. 2013. Changes in nitrogen use traits associated with genetic improvement for grain yield of maize hybrids released in different decades. Crop Science 53(4):1256-1268 DOI 10.2135/cropsci2012.07.0429.

Hawkesford MJ. 2014. Reducing the reliance on nitrogen fertilizer for wheat production. Journal of Cereal Science 59(3): 276-283 DOI 10.1016/j.jcs.2013.12.001.

Hikosaka K. 2004. Interspecific difference in the photosynthesis-nitrogen relationship: patterns, physiological causes, and ecological importance. Journal of Plant Research 117(6):481-494 DOI 10.1007/s10265-004-0174-2.

Kant S, Bi YM, Rothstein SJ. 2011. Understanding plant response to nitrogen limitation for the improvement of crop nitrogen use efficiency. Journal of Experimental Botany 62(4):14901509 DOI 10.1093/jxb/erq297.

Li Q, Wu YW, Chen W, Jin R, Kong FL, Ke YP, Shi HC, Yuan JC. 2017. Cultivar differences in root nitrogen uptake ability of maize hybrids. Frontiers in Plant Science 8:1060 DOI 10.3389/fpls.2017.01060.

Liu Z, Zhu KL, Dong ST, Liu P, Zhao B, Zhang JW. 2017. Effects of integrated agronomic practices management on root growth and development of summer maize. European Journal of Agronomy 84: 140-151 DOI 10.1016/j.eja.2016.12.006.

Lynch JP. 2013. Steep, cheap and deep: an ideotype to optimize water and $\mathrm{N}$ acquisition by maize root systems. Annals Botany 112(2): 347-357 DOI 10.1093/aob/mcs293.

Mi GH, Chen FJ, Wu QP, Lai NW, Yuan LX, Zhang FS. 2010. Ideotype root architecture for efficient nitrogen acquisition by maize in intensive cropping systems. Science China-Life Science 53(12): 1369-1373 DOI 10.1007/s11427-010-4097-y. 
427

428

429

430

431

432

433

434

435

436

437

438

439

440

441

442

443

444

445

446

447

448

449

450

451

452

453

454

455

456

457

458

459

460

461

462

463

464

465

466

Morosini JS, Mendonca LDF, Lyra DH, Galli G, Vidotti MS, Fritsche-Neto R. 2017. Association mapping for traits related to nitrogen use efficiency in tropical maize lines under field conditions. Plant and Soil 421(1-2): 453-463 DOI 10.1007/s11104-017-3479-3.

Mu XH, Chen QW, Chen FJ, Yuan LX, Mi GH. 2016. Within-Leaf Nitrogen Allocation in Adaptation to Low Nitrogen Supply in Maize during Grain-Filling Stage. Frontiers in Plant Science 7:699 DOI 10.3389/fpls.2016.00699.

Nelson DW, Sommers LE. 1973. Determination of total nitrogen in plant material. Agronomy Journal 65(1):109-112 DOI 10.2134/agronj1973.00021962006500010033x.

Peng YF, Zeng XT, Houx JH, Boardman DL, Li CJ, Fritschi FB. 2016. Pre- and post-silking carbohydrate concentrations in maize ear-leaves and developing ears in response to nitrogen availability. Crop Science 56(6): 3218-3227 DOI 10.2135/cropsci2016.03.0183.

Sinclair TR, Horie T. 1989. Leaf nitrogen, photosynthesis, and crop radiation use efficiency: A review. Crop Science 29(1): 90-98 DOI 10.2135/cropsci1989.0011183X002900010023x.

Talabi AO, Badu-Apraku B, Fakorede MAB. 2017. Genetic variances and relationship among traits of an early maturing maize population under drought-stress and low nitrogen environments. Crop Science 57(2): 1-12 DOI 10.2135/cropsci2016.03.0177.

Tester M, Langridge P. 2010. Breeding technologies to increase crop production in a changing world. Science 327(5967):818-822 DOI 10.1126/science.1183700.

Tian QY, Chen FJ, Zhang FS, Mi GH. 2005. Possible involvement of cytokinin in nitratemediated root growth in maize. Plant Soil 277(1-2):185-196 DOI 10.1007/s11104-0056837-5.

Tian QY, Chen FJ, Zhang FS, Mi GH. 2006. Genotypic difference in nitrogen acquisition ability in maize plants is related to the coordination of leaf and root growth. Journal of Plant Nutrition. 29(2): 317-330 DOI 10.1080/01904160500476905.

Tian QY, Chen FJ, Liu JX, Zhang FS, Mi GH. 2008. Inhibition of maize root growth by high nitrate supply is correlated with reduced IAA levels in roots. Plant Physiology 165, 942951 DOI 10.1016/j.jplph.2007.02.011.

Wang QX, Wang P, Yang XY, Zhai ZX, Wang XL, Shen LX. 2003. Effects of nitrogen application time on root distribution and its activity in maize (Zea mays L.). Scientia Agricultura Sinica 36(12):1469-1475 DOI 10.3321/j.issn:0578-1752.2003.12.008

Wang XH, Zhang L, Liu SL, Cao YJ, Wei WW, Liu CG, Wang YJ, Bian SF, Wang LC. 2014. Grain Filling Characteristics of Maize Hybrids Differing in Maturities. Scientia Agricultura Sinica 47(18): 3557-3565 DOI 10.3864/j.issn.0578-1752.2014.18.004

Wang Y, Mi GH, Chen FJ, Zhang JH, Zhang FS. 2004. Response of root morphology to nitrate supply and its contribution to nitrogen accumulation in maize. Journal of Plant Nutrition 27(12): 2189-2202. DOI 10.1081/PLN-200034683.

Wasson AP, Richards RA, Chatrath R, Misra SC, Prasad SVV, Rebetzke GJ, Kirkegaard JA. 2012. Traits and selection strategies to improve root systems and water uptake in waterlimited wheat crops. Journal of Experimental Botany 63(9):3485-3498 DOI $10.1093 / \mathrm{jxb} / \mathrm{ers} 111$. 
467

468

469

470

471

472

473

474

475

476

477

478

479

480

481

482

483

484

485

486

487

488

489

490

White PJ, George TS, Gregory PJ, Bengough AG, Hallett PD, McKenzie BM. 2013. Matching roots to their environment. Annals of Botany 112(2):207-222 DOI 10.1093/aob/mct123.

Wu QP, Chen FJ, Chen YL, Yuan LX, Zhang FS, Mi GH. 2011. Root growth in response to nitrogen supply in Chinese maize hybrids released between 1973 and 2009. Science China Life Sciences 54(7): 642-650 DOI 10.1007/s11427-011-4186-6.

Wu YS, Liu WG, Li XH, Li MS, Zhang DG, Hao ZF, Weng, JF, Xu YB, Li B, Zhang SH, Xie CX. 2011. Low-nitrogen stress tolerance and nitrogen agronomic efficiency among maize inbreds: comparison of multiple indices and evaluation of genetic variation. Euphytica 180(2): 281-290 DOI 10.1007/s10681-011-0409-y.

Xue YG, Duan H, Liu LJ, Wang ZQ, Yang JC, Zhang JH. 2013. An improved crop management increases grain yield and nitrogen and water use efficiency in rice. Crop Science 53(1): 271 284 DOI 10.2135/cropsci2012.06.0360.

York LM, Galindo-Castaneda T, Schussler JR, Lynch JP. 2015. Evolution of US maize (Zea mays L.) root architectural and anatomical phenes over the past 100 years corresponds to increased tolerance of nitrogen stress. Journal of Experimental Botany 66(8), 2347-2358 DOI 10.1093/jxb/erv074.

Zhang XZ, Tan GR, Huang YJ. 1994. Experimental Technology of Plant Physiology. Liaoning Science and Technology Press, Shenyang, China, pp. 51-75 (in Chinese).

Zhang XB, Xu MG, Liu J, Sun N, Wang BR, Wu LH. 2016. Greenhouse gas emissions and stocks of soil carbon and nitrogen from a 20-year fertilized wheat-maize intercropping system: a model approach. Journal Environmental Management 167(1): 105-114 DOI 10.1016/j.jenvman.2015.11.014.

Zhao B, Dong ST, Zhang JW, Liu P. 2013. Effects of controlled-release fertiliser on nitrogen use efficiency in summer maize. PLoS ONE 8(8):e70569 DOI 10.1371/journal.pone.0070569. 


\section{Table $\mathbf{1}$ (on next page)}

Analysis-of-variance of grain yield, yield components, shoot nitrogen uptake and nitrogen use efficiency of maize between/among hybrid variety and nitrogen application rates in 2014 and 2015.

ns Not significant at the $\mathrm{P}=0.05$ level. * Significant at the $\mathrm{P}=0.05$ level. $* *$ Significant at the $P=0.01$ level. $¥$ Significant at the $P=0.1$ level. AEN, agronomic efficiency of nitrogen fertilizer $\left(\mathrm{kg} \mathrm{kg}^{-1}\right)$; PFPN, nitrogen partial factor productivity $\left(\mathrm{kg} \mathrm{kg}^{-1}\right)$; NUtE, nitrogen utilization efficiency $\left(\mathrm{kg} \mathrm{kg}^{-1}\right)$ 
1

\begin{tabular}{|c|c|c|c|c|c|c|c|c|}
\hline Year & Source of variation & Grain yield $\left(\mathrm{t} \mathrm{hm}^{-2}\right)$ & 100-dry grain weight(g) & Grain number $\left(\right.$ ear $\left.^{-1}\right)$ & $\begin{array}{l}\text { Shoot nitrogen uptake }(\mathrm{kg} \\
\left.\qquad \mathrm{hm}^{-2}\right)\end{array}$ & AEN & PFPN & $\begin{array}{c}\text { NUt } \\
\text { E }\end{array}$ \\
\hline \multirow[t]{3}{*}{2014} & Hybrid variety $(\mathrm{H})$ & $* *$ & $* *$ & ns & $* *$ & $*$ & $*$ & $* *$ \\
\hline & $\mathrm{N} \operatorname{rates}(\mathrm{N})$ & $* *$ & $* *$ & $* *$ & $* *$ & $* *$ & $* *$ & $* *$ \\
\hline & $\mathrm{H}^{*} \mathrm{~N}$ & $*$ & $*$ & ns & $t$ & $*$ & $*$ & $*$ \\
\hline \multirow[t]{3}{*}{2015} & Hybrid variety(H) & $*$ & $*$ & $\mathrm{~ns}$ & $* *$ & $*$ & $*$ & $* *$ \\
\hline & $\mathrm{N}$ rates $(\mathrm{N})$ & $* *$ & $* *$ & $* *$ & $* *$ & $* *$ & $* *$ & $* *$ \\
\hline & $\mathrm{H}^{*} \mathrm{~N}$ & + & + & ns & $*$ & $*$ & $*$ & $*$ \\
\hline
\end{tabular}

2 


\section{Table 2 (on next page)}

Grain yield and yield components of maize hybrid varieties under four nitrogen application rates in 2014 and 2015. 
1

\begin{tabular}{|c|c|c|c|c|c|c|c|}
\hline \multirow[t]{2}{*}{$\mathrm{N}$ rate } & \multirow{2}{*}{$\begin{array}{l}\text { Hybrid } \\
\text { variety }\end{array}$} & 2014 & \multicolumn{5}{|c|}{2015} \\
\hline & & $\begin{array}{c}\text { 100-dry grain } \\
\text { weight } \\
\text { (g) }\end{array}$ & $\begin{array}{l}\text { Grain } \\
\text { number } \\
\left(\text { ear }^{-1}\right)\end{array}$ & $\begin{array}{l}\text { Grain yield } \\
\left(\mathrm{t} \mathrm{hm}^{-2}\right)\end{array}$ & $\begin{array}{c}\text { 100-dry grain } \\
\text { weight (g) }\end{array}$ & $\begin{array}{c}\text { Grain number } \\
\quad\left(\mathrm{ear}^{-1}\right)\end{array}$ & $\begin{array}{c}\text { Grain } \\
\text { yield } \\
\left(\mathrm{t} \mathrm{hm}^{-2}\right)\end{array}$ \\
\hline N0 & QS101 & $28.5 \mathrm{c}$ & $417.56 \mathrm{c}$ & $7.36 \mathrm{c}$ & $27.73 d$ & $428.67 \mathrm{~d}$ & $7.71 \mathrm{c}$ \\
\hline N150 & QS101 & $28.65 \mathrm{c}$ & $488.81 \mathrm{ab}$ & $8.44 \mathrm{~b}$ & $30.97 \mathrm{~b}$ & $496.45 b$ & $8.74 \mathrm{~b}$ \\
\hline N225 & QS101 & $31.34 \mathrm{a}$ & $506.22 \mathrm{ab}$ & $9.65 \mathrm{a}$ & $32.64 a$ & 523.49ab & $10.34 \mathrm{a}$ \\
\hline N300 & QS101 & $31.17 \mathrm{a}$ & $502.81 \mathrm{ab}$ & $9.76 a$ & $32.28 \mathrm{a}$ & $495.3 b$ & $10 \mathrm{a}$ \\
\hline N0 & ZD958 & $30.02 \mathrm{~b}$ & $456.95 \mathrm{cb}$ & $8.45 \mathrm{~b}$ & $29.34 c$ & $461.73 \mathrm{c}$ & $8.69 \mathrm{~b}$ \\
\hline N150 & ZD958 & $31.74 a$ & $523.87 \mathrm{a}$ & $9.57 \mathrm{a}$ & $32.51 \mathrm{a}$ & $519.96 \mathrm{ab}$ & $9.78 \mathrm{a}$ \\
\hline N225 & ZD958 & $31.44 \mathrm{a}$ & $508.64 \mathrm{ab}$ & $9.66 \mathrm{a}$ & $32.68 \mathrm{a}$ & $558.13 \mathrm{a}$ & $10.26 \mathrm{a}$ \\
\hline N300 & ZD958 & $31.58 \mathrm{a}$ & $544.07 \mathrm{ab}$ & $9.72 \mathrm{a}$ & $32.87 \mathrm{a}$ & 518.93ab & $10.06 \mathrm{a}$ \\
\hline
\end{tabular}

2 


\section{Table 3 (on next page)}

Shoot nitrogen uptake and nitrogen use efficiency of two maize hybrid varieties under four nitrogen application rates in 2014 and 2015.

AEN, agronomic efficiency of nitrogen fertilizer $\left(\mathrm{kg} \mathrm{kg}^{-1}\right)$; PFPN, nitrogen partial factor productivity $\left(\mathrm{kg} \mathrm{kg}^{-1}\right)$; NUtE, nitrogen utilization efficiency $\left(\mathrm{kg} \mathrm{kg}^{-1}\right)$ 


\begin{tabular}{|c|c|c|c|c|c|c|c|c|c|}
\hline \multirow[b]{2}{*}{$\mathrm{N}$ rate } & \multirow[b]{2}{*}{ Hybrid variety } & \multirow{2}{*}{$\begin{array}{c}2014 \\
\text { Shoot N uptake }\left(\mathrm{kg} \mathrm{hm}^{-2}\right)\end{array}$} & \multicolumn{7}{|c|}{2015} \\
\hline & & & AEN & PFPN & NUtE & Shoot $\mathrm{N}$ uptake $\left(\mathrm{kg} \mathrm{hm}^{-2}\right)$ & AEN & PFPN & NUtE \\
\hline No & QS101 & $115 f$ & - & - & $54.91 \mathrm{~b}$ & $117 f$ & - & - & $56.73 b$ \\
\hline N150 & QS101 & $150 \mathrm{~d}$ & $7.18 b$ & $56.27 \mathrm{~b}$ & $48.47 \mathrm{~d}$ & $148 \mathrm{~d}$ & $6.86 \mathrm{~b}$ & $58.25 \mathrm{~b}$ & $50.66 \mathrm{~d}$ \\
\hline N225 & QS101 & $190 \mathrm{~b}$ & $10.14 \mathrm{a}$ & $42.87 \mathrm{c}$ & $43.71 \mathrm{e}$ & $186 \mathrm{~b}$ & $11.69 \mathrm{a}$ & $45.95 \mathrm{c}$ & $47.8 \mathrm{e}$ \\
\hline N300 & QS101 & $206 a$ & $7.99 b$ & $32.54 \mathrm{c}$ & $40.89 \mathrm{e}$ & $189 \mathrm{a}$ & $7.65 b$ & $33.34 \mathrm{c}$ & $45.42 \mathrm{e}$ \\
\hline N0 & ZD958 & $121 \mathrm{e}$ & - & - & $59.78 \mathrm{a}$ & $126 \mathrm{e}$ & - & - & $59.19 \mathrm{a}$ \\
\hline N150 & ZD958 & $156 \mathrm{c}$ & $7.46 b$ & $63.8 \mathrm{a}$ & $52.65 \mathrm{c}$ & $157 \mathrm{c}$ & $7.26 b$ & $65.17 \mathrm{a}$ & $53.65 c$ \\
\hline $\mathrm{N} 225$ & ZD958 & $191 b$ & $5.35 \mathrm{~b}$ & $42.91 \mathrm{c}$ & $43.39 \mathrm{e}$ & $184 b$ & $7 \mathrm{~b}$ & $45.6 \mathrm{c}$ & $47.94 \mathrm{e}$ \\
\hline N300 & ZD958 & $205 \mathrm{a}$ & $4.22 \mathrm{c}$ & $32.4 \mathrm{c}$ & $40.84 \mathrm{e}$ & $191 \mathrm{a}$ & $4.57 \mathrm{c}$ & $33.52 \mathrm{c}$ & $45.19 \mathrm{e}$ \\
\hline
\end{tabular}




\section{Table 4 (on next page)}

Characteristic parameters of two maize hybrid varieties under four nitrogen application rates during grain-filling stage in 2014 and 2015.

N0-QS, N150-QS, N225-QS, and N300-QS represent hybrid variety QS101 under 0,150,225, and $300 \mathrm{~kg} \mathrm{hm}^{-2}$ nitrogen application rates respectively; N0-ZD, N150-ZD, N225-ZD, N300-ZD represent hybrid variety ZD958 under $0,150,225$, and $300 \mathrm{~kg} \mathrm{hm}^{-2}$ nitrogen application rates respectively. Tmax, the days needed for reaching the maximum grain filling rate (d); Wmax, the grain weight at the maximum grain filling rate $(\mathrm{mg})$; Gmax, the maximum grain-filling rate $\left(\mathrm{mg} \mathrm{grain}^{-1} \mathrm{~d}^{-1}\right)$; T0.99, the final grain filling time (the time of grain weight reaches $99 \%$, d) ; Gave, the average grain-filling rate ( $m g$ grain $\left.{ }^{-1} \mathrm{~d}^{-1}\right)$ 
1

\begin{tabular}{|c|c|c|c|c|c|c|c|c|c|}
\hline Year & Parameters & N0-QS & N150-QS & N225-QS & N300-QS & N0-ZD & N150-ZD & $\mathrm{N} 225-\mathrm{ZD}$ & N300-ZD \\
\hline \multirow[t]{8}{*}{2014} & A & 21.85 & 25.72 & 28.09 & 28.46 & 25.44 & 28.15 & 28.22 & 28.38 \\
\hline & B & 108.90 & 97.59 & 104.93 & 123.51 & 59.33 & 61.62 & 60.40 & 68.62 \\
\hline & $\mathrm{C}$ & 0.21 & 0.20 & 0.20 & 0.19 & 0.19 & 0.19 & 0.19 & 0.19 \\
\hline & Tmax & 22.59 & 22.95 & 23.51 & 24.95 & 21.07 & 21.32 & 21.85 & 22.43 \\
\hline & Gmax & 1.13 & 1.28 & 1.39 & 1.37 & 1.23 & 1.36 & 1.32 & 1.34 \\
\hline & Wmax & 10.92 & 12.86 & 14.05 & 14.23 & 12.72 & 14.07 & 14.11 & 14.19 \\
\hline & Gave & 0.48 & 0.55 & 0.60 & 0.58 & 0.56 & 0.62 & 0.60 & 0.60 \\
\hline & Т0.99 & 44.72 & 45.97 & 46.72 & 48.75 & 44.79 & 45.10 & 46.33 & 46.80 \\
\hline \multirow[t]{8}{*}{2015} & A & 22.95 & 26.99 & 31.49 & 31.52 & 26.56 & 29.86 & 31.25 & 31.13 \\
\hline & $\mathrm{B}$ & 64.47 & 62.79 & 68.15 & 79.76 & 42.08 & 44.72 & 44.32 & 50.17 \\
\hline & $\mathrm{C}$ & 0.19 & 0.18 & 0.18 & 0.18 & 0.18 & 0.18 & 0.18 & 0.18 \\
\hline & Tmax & 22.36 & 22.78 & 23.41 & 24.94 & 20.79 & 21.08 & 21.65 & 22.25 \\
\hline & Gmax & 1.07 & 1.23 & 1.42 & 1.38 & 1.19 & 1.35 & 1.37 & 1.37 \\
\hline & Wmax & 11.48 & 13.49 & 15.75 & 15.76 & 13.28 & 14.93 & 15.62 & 15.57 \\
\hline & Gave & 0.48 & 0.56 & 0.64 & 0.61 & 0.57 & 0.63 & 0.65 & 0.64 \\
\hline & T0.99 & 47.02 & 48.06 & 48.88 & 51.12 & 46.34 & 46.58 & 47.89 & 48.36 \\
\hline
\end{tabular}

2 


\section{Figure 1 (on next page)}

Daily mean temperature, precipitation during the maize growing seasons in 2014 (A) and 2015 (B) at Yangling District, Shaanxi Province, China. 

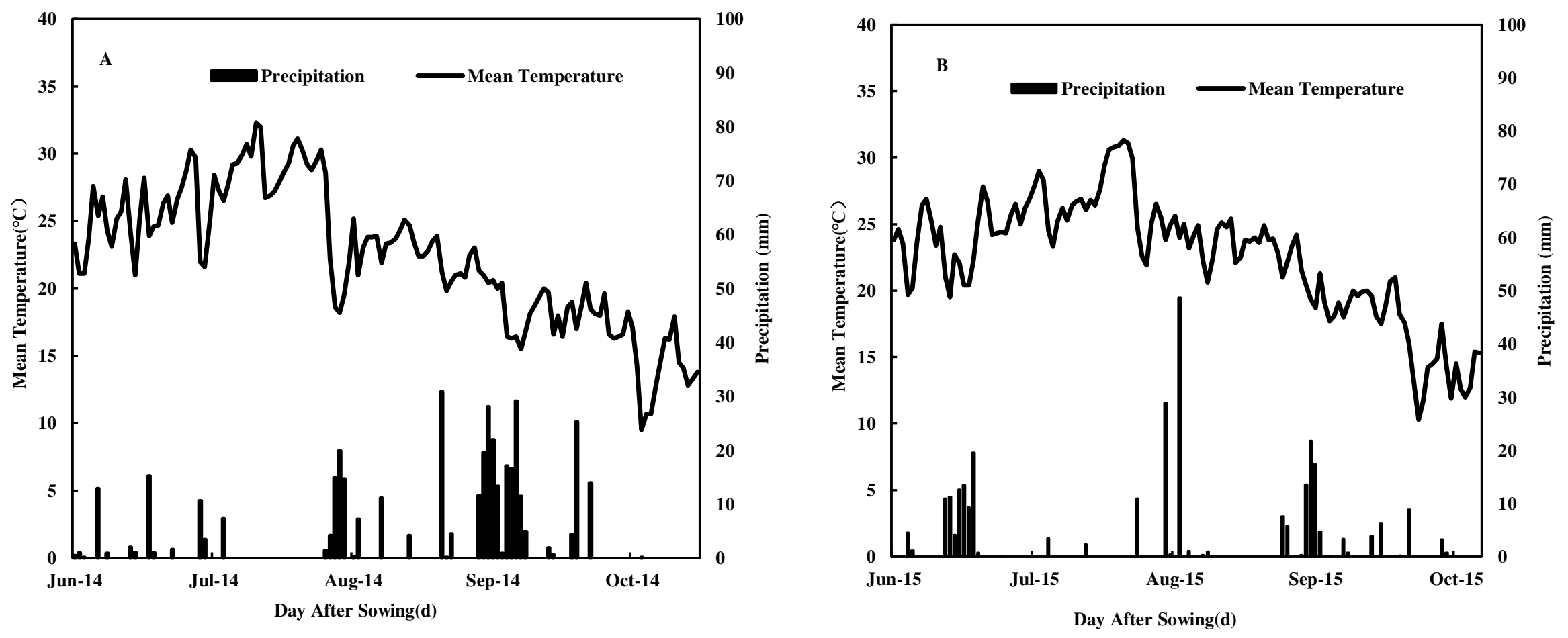
Figure 2 (on next page)

Shoot dry matter (SDM) at anthesis (A) and maturity (B), root dry matter (RDM, C) and root/shoot at anthesis (D) of maize under various nitrogen rates in 2014 and 2015.

Vertical bars represent \pm standard error of the mean $(n=3)$ where these exceed the size of the symbol. Different lowercase letters above the column indicate statistical significance at the $P=0.05$ level within the same $N$ rate, and ns means not significant at the $P=0.05$ level. 

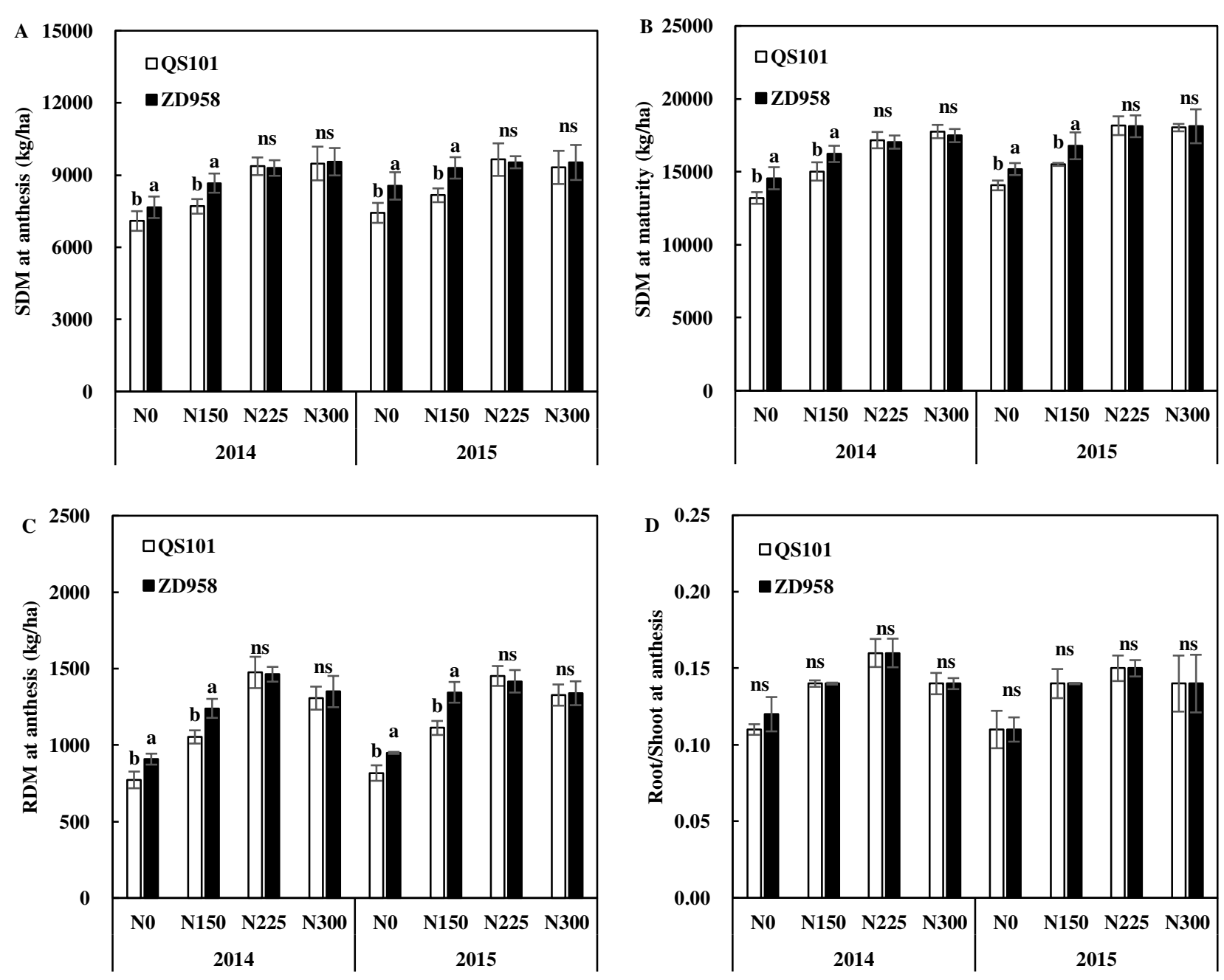
Figure 3 (on next page)

Root dry weight of maize in $0-20 \mathrm{~cm}(A), 20-40 \mathrm{~cm}(B)$ and $40-60 \mathrm{~cm}$ (C) soil layer at anthesis of two hybrid variety under various nitrogen $(\mathrm{N})$ application rates in 2014 and 2015.

Data are averages observed for three replications. Vertical bars represent \pm standard error of the mean $(n=3)$ where these exceed the size of the symbol. Different lowercase letters above the column indicate statistical significance at the $P=0.05$ level within the same $N$ rate, and ns means not significant at the $\mathrm{P}=0.05$ level. 

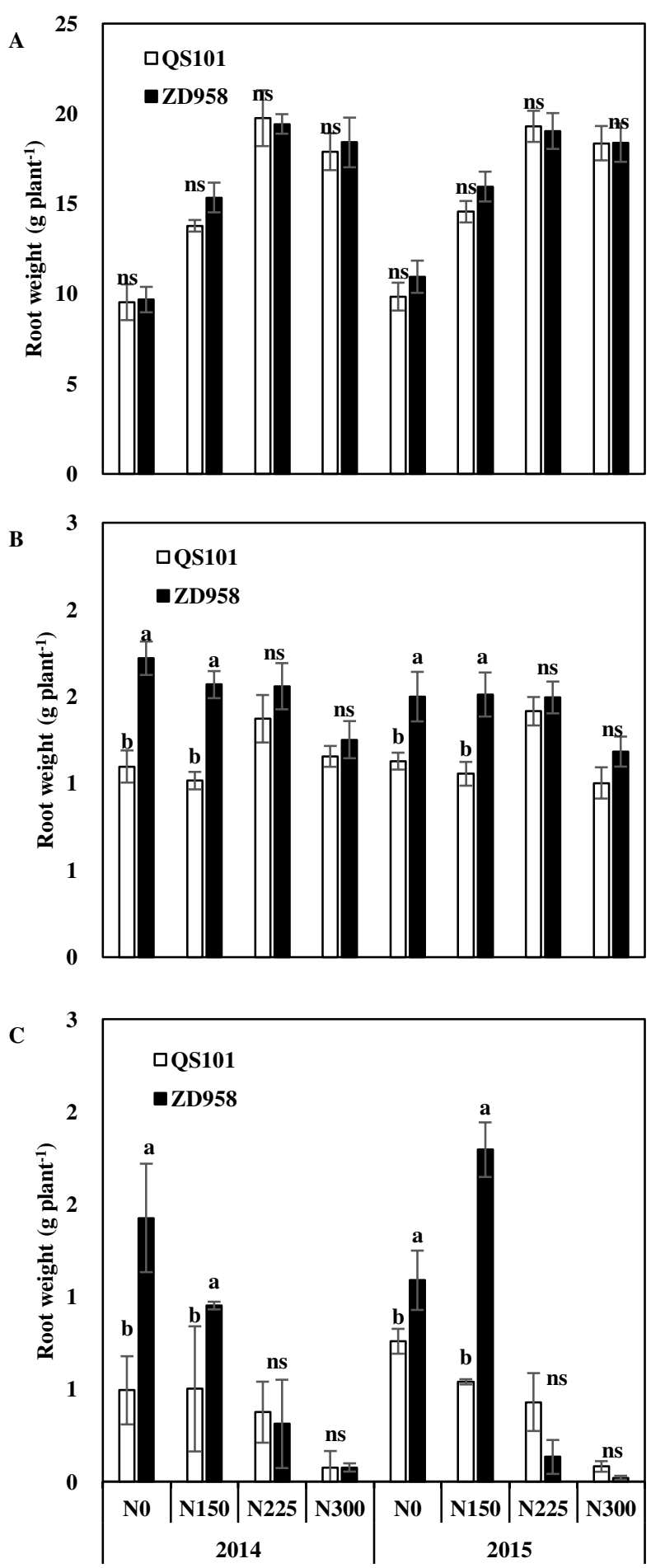
Figure 4 (on next page)

Root length of maize in $0-20 \mathrm{~cm}(\mathrm{~A}), 20-40 \mathrm{~cm}(\mathrm{~B})$ and $40-60 \mathrm{~cm}$ (C) soil layer at anthesis of two hybrid variety under various nitrogen $(\mathrm{N})$ application rates in 2014 and 2015.

Data are averages observed for three replications. Vertical bars represent \pm standard error of the mean $(n=3)$ where these exceed the size of the symbol. Different lowercase letters above the column indicate statistical significance at the $\mathrm{P}=0.05$ level within the same $\mathrm{N}$ rate, and ns means not significant at the $\mathrm{P}=0.05$ level. 

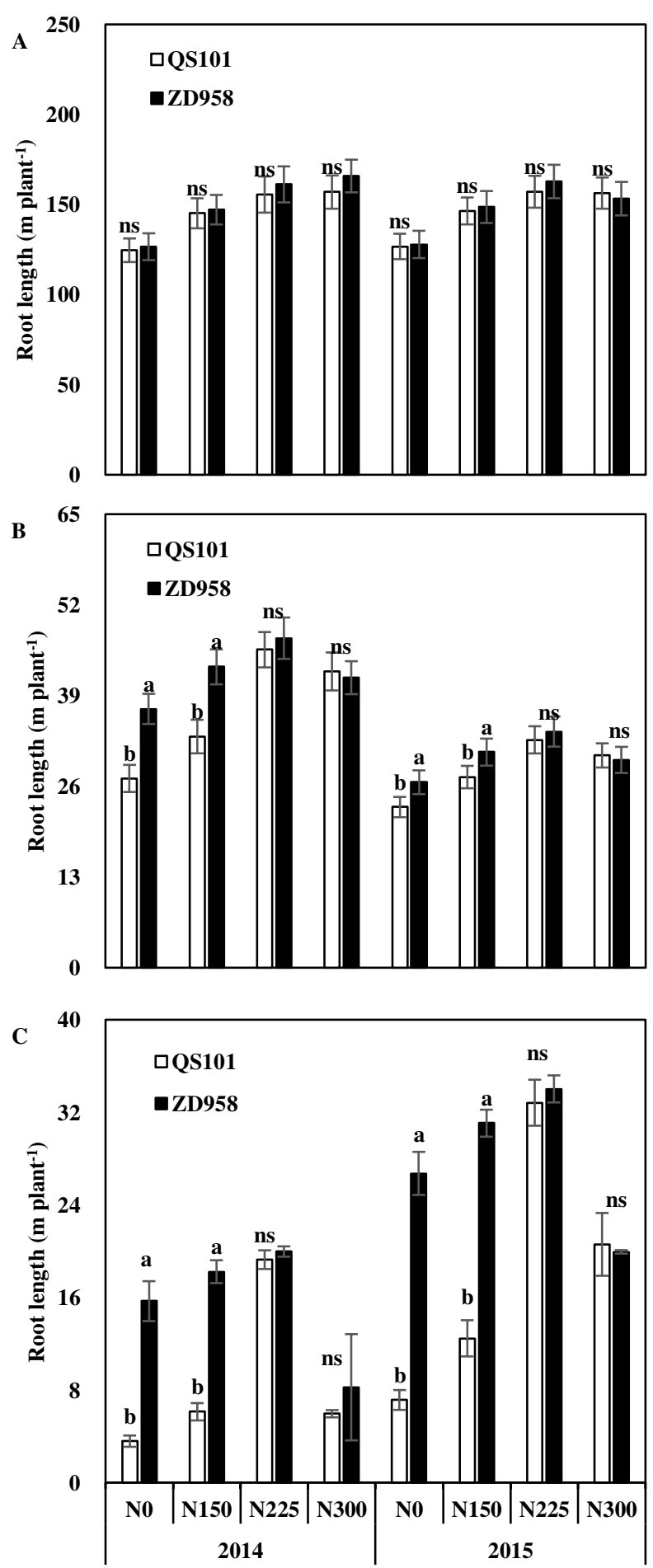
Figure 5 (on next page)

Root active absorption area of maize in $0-20 \mathrm{~cm}(\mathrm{~A}), 20-40 \mathrm{~cm}(\mathrm{~B})$ and $40-60 \mathrm{~cm}(\mathrm{C})$ soil layer at anthesis of two hybrid variety under various nitrogen $(\mathrm{N})$ application rates in 2014 and 2015.

Data are averages observed for three replications. Vertical bars represent \pm standard error of the mean $(n=3)$ where these exceed the size of the symbol. Different lowercase letters above the column indicate statistical significance at the $P=0.05$ level within the same $N$ rate, and ns means not significant at the $\mathrm{P}=0.05$ level. 

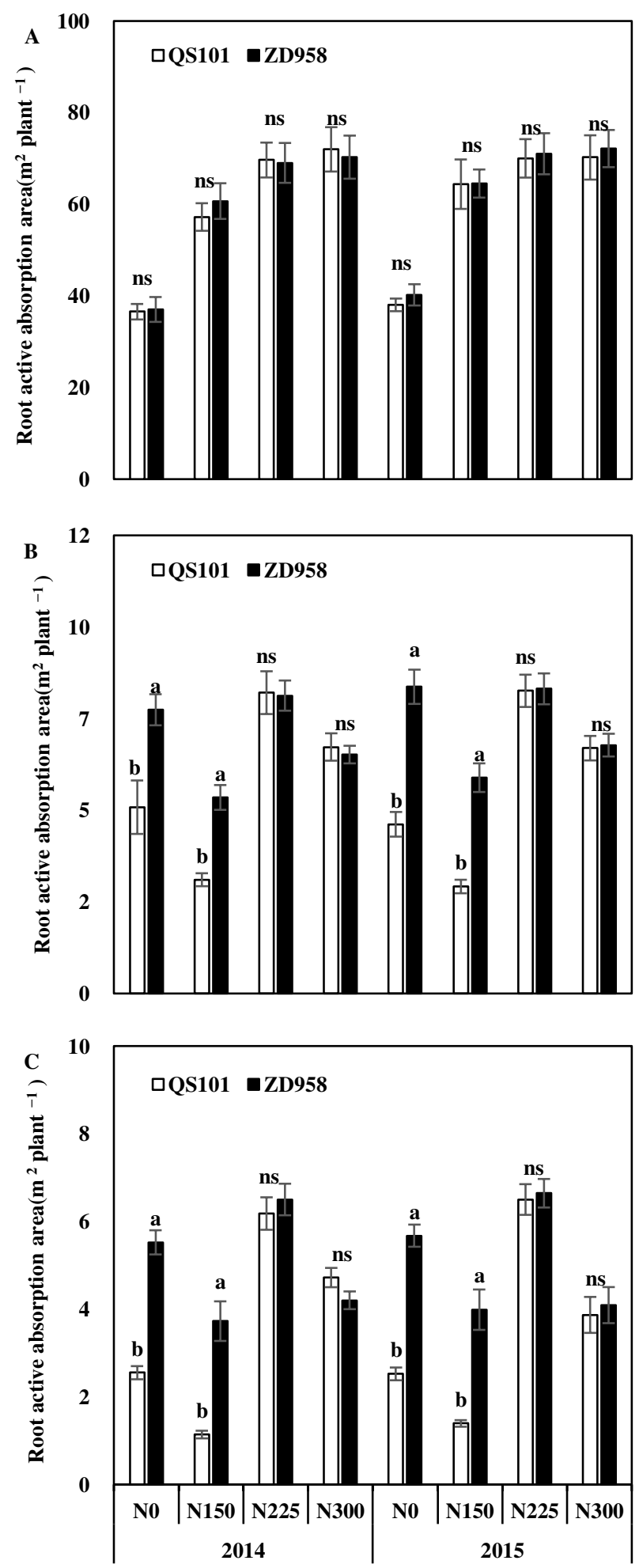
Figure 6 (on next page)

Specific leaf nitrogen (SLN, A), net photosynthetic rate $(\mathrm{Pn}, \mathrm{B})$ and photosynthesitic nitrogen use efficiency (PNUE, C) of two maize hybrid varieties under four nitrogen rates at anthesis in 2014 and 2015.

Vertical bars represent \pm standard error of the mean $(n=3)$ where these exceed the size of the symbol. Different lowercase letters above the column indicate statistical significance at the $P=0.05$ level within the same $N$ rate, and ns means not significant at the $P=0.05$ level. 

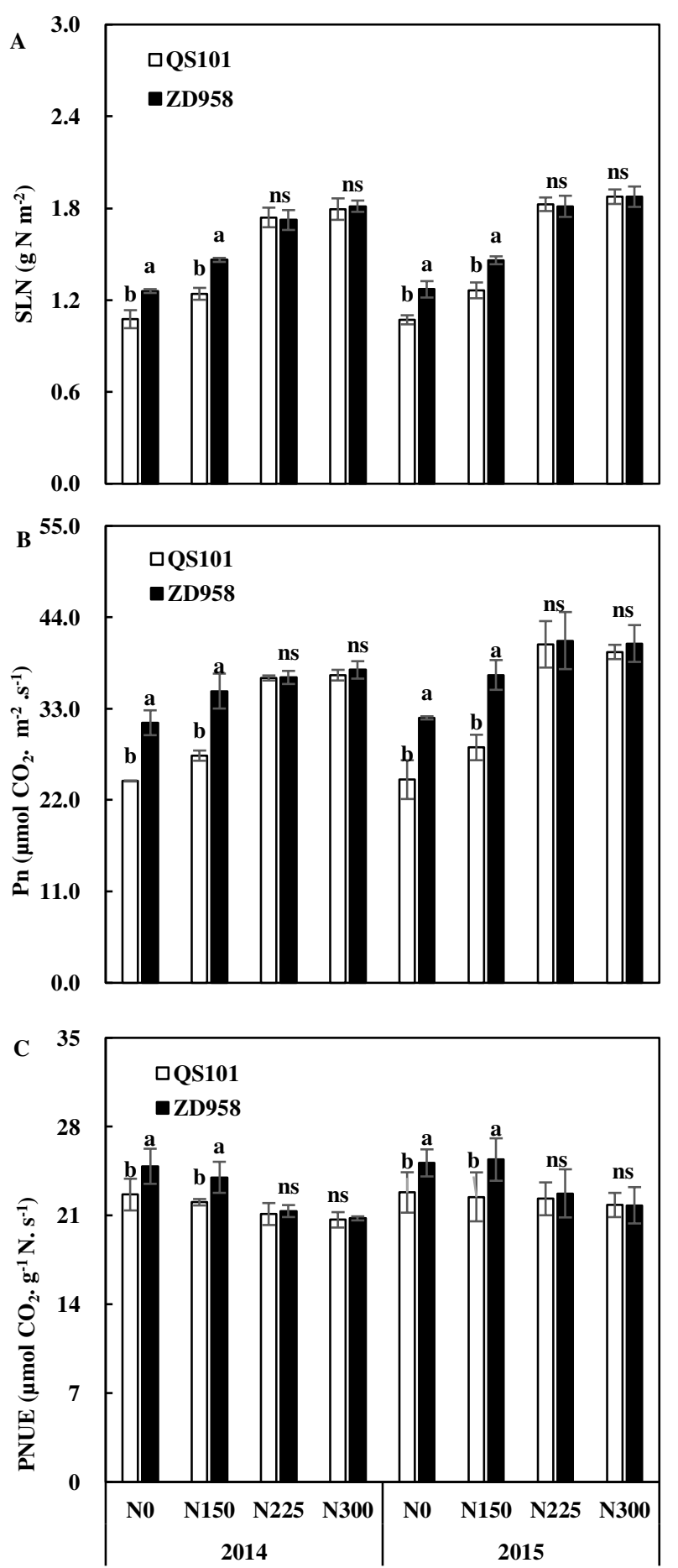